\title{
Stylistics of Teaching and Learning Process of Language through Literature: A Symbiotic Relationship and Spontaneous Production of Creative Pedagogy
}

\author{
Moneer Ismail a* \\ a Al-Quds Open University, Palestine
}

\begin{abstract}
:
This study showed that there is a strong link between literature, which is considered a living or symbiotic link. Therefore, the study indicated that the relationship should be examined and used to improve the teaching and learning process which are affected by literature and language at all levels of teaching.

Language teaching through literature first helps teachers recognize the use of language in order to improve their own competence and use language as a social phenomenon, rather than as an exclusive branch of learning, another thing is that the use of literature transforms the classroom as a stage in which there is a real practice of the language of communication. The study also showed that literature is an open window to the target language culture and helps learners to develop a better understanding of the "other", as well as to enhance their intercultural competence.

This paper has been focused or discussed on how to use literature in language classes so as to improve student knowledge of English language. She focused on employing literature as a well-known medium for teaching English as a foreign language. Exploring new ways of teaching English is the need of the hour. One of the best practices in teaching English through literature, which is calm and effective. The scope of this paper is to give some leading methods which are used by English language teachers and on how to pursue or use the potential of literary texts in their FL classroom by carefully planning activities and creating a platform for positive feedback for learners with skill, and contributing to the author's personal experience in adopting literature a powerful way To learn the language for learners and enhance communication competence.
\end{abstract}

\section{Keywords: Learning Process; Learning Process; Creative Pedagogy.}

\section{Introduction:}

Literature could be regarded as a rich source of "original data" because it indicates two characteristics in its written form: the first is the "language used", that is, the employment of linguistics by those who have skilled it in vogue meant for original speakers; the second is the aesthetic representation of the spoken language that aims to establish or form Language in a specific cultural context.(Onuekwusi .2013,P.31), "Identifies that teaching language through literature help teachers first to acquaint themselves with language use to develop their own competence and understand language as a social phenomenon, and not as an exclusive branch of learning.in other words I would say that literature in all its forms it transforms the classrooms as the stage in which there is real practice of communicative language. It also helps teachers to consider language as entailing social acceptability" In different methods, they could have the classroom language as having affinities to the extrinsic language. As an outcome, this will increase interaction to the scale of social undertaking. It can be familiar that it is essential for

\footnotetext{
* Corresponding author

Email address: mismael@qou.edu (Moneer Ismail)

DOI: https://doi.org/10.31559/baes2020.4.1.1

Received Date: $23 / 12 / 2019$

Accepted Date: 20/3/2020
} 
scholars to improve their language efficiency by learning how to convey content in English, but also that they improve their interaction competence, which will permit them to transmit messages, use the language to interact, and communicate with others, which is finally have the primary function of a language. It is widely known that a literary text with richness and different diversity can motivate language scholars and can be used to elicit a wide range of reaction from students.

In concentration of the aforementioned, the sense of this study focuses on examining the factual issue that there is a correlated connection between literature and language. The study Shows how literature could be integrated with language usage in preparing a creative teaching and learning outcome. Good literature can be a good support for cultural understanding or acculturation; progress of language and competence; differentiation in decision; emotional progress and settlement. Provide positive and life-oriented situations.

\section{The Concept and Functions of Literature:}

As a matter of fact, that literature has been considered as a familiar key of language using, manipulating, learning and teaching. (Onuekwusi,19,2013), "Literature is any imaginative and beautiful creation in words whether oral or written, which explores man as he struggles to survive in his existential position and which provides entertainment, information, education and excitement to its audience". Even though literature is defined by (O'Connell, F. 2009) as an accurate experience to grasp the spirit of literature, it is pertinent to point out that not all literature to be considered as an imaginative genre. As a matter of fact, I can conclude that several literary versions are related to facts, and are depended on rationalization by considering them as related to prose type which are sorted into two styles, fiction and non-fiction. Literature that is factual which could be consider as under the title genuine literature, in other words, it is a written work to what we call it a prose genre. In other words that is to say that language is the main producer of that literature. The term "literature" is considered in two main meanings. First, it is done to any written themes in language to what we call it literature. Second, it is an expression done to indicate to one of the study themes that is used by scholars or a university field of study; and it is this second content that practiced to students in that scope or field. It is depended on that point that it is normally considered that Literature is language in different form or usage.

Literature aids to generate the student's language in practice because it awakens learner's enthusiasm and preserves in them a ready-made attribution to read. Furthermore, it supports the seekers to improve language perfection and the ability to discuss what is used and understood". As a learning field, there are some magnitude themes Literature operates. Used in different shape the complete gist of processing Literature as a learning field or scope is for the learners to extract several advantages. Ayo (2003, p. 128) shows the advantages as the different interests of Literature. According to his understanding, "the utilities of Literature could be educational, cultural, moral, recreational and socio-political". As a scholar I would like to help the thoroughness or containment of Literature in the linguistic form in teaching because it brings worth genuine knowledge, improves personal expression and support sharing to learners' cultural as well as language inseminate. Still on the interests of Literature, (Lazar 1993) comes up with five facts for forming literature in ELT to contain the following:

1) encouraging knowledge

2) motivating linguistic conquest

3) developing learners' linguistic forms

4) improving learners' expressing and discussing abilities

5) edifying the entire learner.

\section{The strong relevant relationship between Literature and Language:}

The coexistence between Literature and language is summarized aforementioned according to (Retrieved April ,2005, P.37) also he has mentioned that English teaching literature and language is not only coexist together but also interlinked. Literature presupposes language because it is with a language tool in which literature is embodied. Therefore, it seems absurd to study literature without a language in the foreground or study language without literature plays a prominent role. This view is based on the view that the best description of the relationship between literature and language is to be coordinated.

In the teaching process, students are aware of a lot of practical value about language usage and language itself. In their literary studies, students meet the language in its most diverse and strong forms, and learn how to study the author's use of them in the context of all the language sources which are available to them. Literature for all reading ages - is a linguistic lexicon that must apply linguistic understanding if it can be examined and valued. In other meanings, I would like to tell that literature shows language at usage. But it also supports the learners to use the language. It provides good examples and stimulates language responses of different types. English teachers not only offer literature, but also literature. They also benefit from it, because they can form correct language as well as its embodiment.

Literature, as a suitable mode of meaning for a text in foreign language, gives us a stimulating knowledge of linguistic interaction. (Carter and Long .1991) similarly agreed that literature is a legal resource and deserves to learn language and teach. Literature depends on language and language gets ornament and enthusiasm through literature. Literature and language are therefore closely linked. According to (Lazar .1993), literary forms should 
be in touch with educated literature because it is an encouraging incentive to accommodate the language, and students appreciate it, and it is fun, it exists in many curriculums and the same thing.

When we be in touch with literature in linguistic form classes, we teach the language. (Barnett, S 2013, P. 23) View that it is simply accepted as it is taken that literature is a viable element of foreign language on an appropriate criterion and that one of the prominent objectives of literature is to use as an ordinary to change the culture of those who use the language they speak or write. Literature is a high element of language use. It can be said that it notifies the most prominent tact that the language user can show. Anyone who needs to use or has a complicated knowledge of the language that drives beyond interest will read literary texts in in their linguistic forms.

Language and Literature are interchangeable in other words they help that the learning process of Language and Literature should go within each other, since literature is perfectly existing together. Some linguists said that since there should be no partition between them, so there is no deep differentiation between language and Literature so Literature told to be preceding language. In the same origin, (Ayo 2003, P. 130) is of the attitude that "through the creative modes of learning and teaching Literature, the learners could be supported to improve credibility within themselves in giving out coherent and cohesive spoken discourses and in ordering sentences into paragraphs with efficient connectors and classify paragraphs into connected and understandable spoken and written".

The results of the studies help in the correct way in which there is full reliance between extensive reading literature, language understanding, and, foremost, real reading. For example, (O'Connell, F.2009, P.13) He argues that reading can bring ready tools to understand the comic in a foreign language. The source also shows that reading literature carrires students' access to large elements of vocabulary in the contexts of their true language. One of the best ways to read literary courses that demonstrate a more effective understanding of meanings is because the whole of any creative writing is the ability to use the appropriate expression to form meaningful sentences that are logically and in sequence. By the way, all writing methods are correct if the author does not have a good order of directed jackish. However, language learning through literature supports in particular the advancement of language-speaking skills. (Guth and Schuster 1997, p. 75) Have accepted with the supporters of literature theory and language relations by insisting that: "A good reader of literature is a good speaker in the language". They also explain the role of reading literature in being able to speak in manipulation.

Literature of prose could be practiced to make learners' have more lexical and however alleviate their learning language strength; which leads to mindful dialogue in major elements in a short story or any literary version which could help learners' perfection of the main parts of novel, within, discussion, description and telling. (Ayo 2003) has discussed in prose practicing, the tact of manipulated reading as well as skimming and scanning can be processed. Ayo has mentioned that, if the learners go through literature effectively then language will be developed, their speaking experience could be enhanced in other meaning a reader of literature one has to be a good speaker of language.

Literature in the advanced stage of learners is known to be learned as an isolated field, considered as a different subject. Processing with a new mode, while others are classified as language teachers are appointed as literature trainers, others are sorted as language teachers. With this classification, the literature teacher teaches literature consistently without assigning elements while English teachers do the same without reference to literature. On the whole, there is no cooperation, support or education between the two categories of instructors, because each one of instructor is considered aside. As we know in this study, this particular situation should be studied to determine the path of innovation that would create space for the discovery and use of the close symbiotic or coexisting relation between literature and language so as to develop the skill of English language use among English learners as a foreign or second language.

\section{Orientation for Learning Literature and English for Motivated Goals:}

Literary virgins are genuine, thoughtful and correlated to learners' lives. They produce the utmost chance, for participation, repercussion, and even though learning lives in them. Literature is rationally awakening our thoughts because it allows students to feel worlds they are not experienced with. This is done through the use of depicting language. In order to experience, the learners will create his thoughtful picture of what the authors are saying. In this meaning, the learners become acting followers in a brainstorming action as he sees. Literaturebased programs concentrate on one's own interpretation of the language so learners start to experience the linguistic method and use this into them.

[1] The literature teacher should not neglect linguistic hints that are limited to dialogue in drama version, so the instructor of the language have to be more specific in order to clarify literary versions in his teaching process of the different parts of the language. In this way, the success or failure of English language students in the classroom must be a collective responsibility of both language and literature teachers and not just the responsibility of the language teacher as it is today. English Literature and teachers must have a common goal to enhance the motivation in using English in their skills. In order to achieve this goal, their vocational training must be designed to be qualified in both English and English so that the teaching of the literature has all the basic skills necessary for teaching the language, while the English teacher must be sufficiently qualified to 
teach the literature. Practice in which Teacher a claims to be a specialist in teaching literature while Teacher B is an expert in English

[2] Literature has to be used as major field of study such as English Language and physics and consider it as a major subject which is compulsory to all learners with regardless to the field of specialization. This practice will make learners to take an advantage of appropriate literature resources to enrich their English language skills.

[3] Learners in both middle and high school should be able to read a significant of many literature versions texts because they will enlarge students' capacity of perception which let them engage in considered language in order to enhance English language proficiency. Literature creates space for students to create a culture of wide-ranging reading, which it is a strong way to address English language incompatibility.

[4] Many reasons considered teachers and students of literature to be satisfied with the literary forms. The test in which literary parts are to be assessed to candidate or student elected in literature tests frustrates the importance of literature in language acquisition.

[5] The last practice whereby only two- or three-times literature is assigned per week is imminent. On the one hand, there is not enough opportunity for the coach to deal with the plan comprehensively for the semester or semester; and in the place of learners, students do not have enough time to work in motivating classes on this topic. Literature must define a logical number of times on the school's schedule as in English program.

[6] The instructor of tests and literature should be involved in the versions of the texts that are absorbed into English culture written in modern English. Copies of written literature must be within the logical linguistic competence of learners and be linked to their social and cultural teaching and acquisition. Although the Chaucerian versions are old and reflect the culture of the ancient English people, these versions could not be useful for effectively acquiring modern or current English.

\section{The real value of taking literary version in language learning and teaching:}

Literature supplies genuine material. The students are discloses to real language patterns from genuine life and literature demonstrates as a useful completion to such data. (Brumfit and Carter,2014) affirm the scope that -a literary version is genuine version, true language in discourse, to which we can reply in a direct way. Such a version safely holds the reader's mind picture and makes fields for the test of the language as well.

Literature supports learners create manipulation abilities. (Lazar,1993) says, -Literature is a specifically good base for creating learners' capacities to indicate meaning and to make explanation. This is because literary texts are often rich in variety grades of meaning, and required that the reader/learner is actively involved in teaching out the unstated implications and assumptions of the literary version.

Literature makes learners to have acquaintance with international causes and thereby stimulates them into reading. Collie and Slater argue that literature presents a much and absolutely different figure of written work that manipulates with the problems human causes. -Though the world of literature is a made the same picture, it describes contextually energetic personalities from different social domains or fields. A reader can find their imaginations, feelings, traditional believes, possessions; what they buy, believe in, fear, enjoy; how they speak and behave behind closed doors. This lively pictured world can hastily offer the non-native reader a sensation for the entries and meditation thoughts that furnished a true society. (Collie, 2011) Narrated that teaching through literature gives more learner's deep thinking into intended language society and reaches the cultural space.

\section{The Use of Literature in English language Classes:}

The chief relation of this study part is to clarify the question "why to have literary versions in EFL classes". Could we consider literature be taken as a language of teaching knowledge in EFL teaching classes?

The English teacher is used to focus on teaching the original parts of the expression in the language. However, in language fluency, it is clarified that English users have stopped with obstacles of understanding. Dynamic communication is more than just getting the grammar and form of the language. In other words, the ability to discuss interaction in all its all texts. For this cause, the usage of literary forms in the English classes could become an educational mode for language and self-development learners.

Literature could enlarge the linguistic form tact because literature will increase language knowledge by having clues of concentration and lexical usage (Povey,1972:182). Practicing literature in EFL classrooms is considerate, "for literature provides us with a convenient source of content for a course in a foreign language, and a truly notional syllabus will need to be constructed round concepts and subject matter which develop in complexity" Clandfield, Lindsay.2005:26). Furthermore, Malley and Duff state that "most attempts to provide motivating and communicative material for learners are strong in technique but weak in any sense of developmental structure"(Malley\&Duff,1986:124)."

For linguists like Collie, Slater, carter, who advocate the idea of having literature in language form lessons, there have been good causes why English Language instructors should use literary texts in their classroom as language-related subjects. Accordingly, why would students want to use literary materials instead of boredom course materials? Therefore, the literature offers a very abundant and diverse variety of written material that is 
"important" and "interesting". The joy that literature gives it's inevitable. Using literature is very pleasing for learners because in this issue they take a different mode of discussing from what students will create.

Collie and Slater (1996: p.3) notified that "literature is a genuine material." By other meaning that the most literary works have specific tasks for the process of Language teaching. some texts are "authentic" samples of language; Therefore, learners of language are opened to authentic language as in dealt in social life that could be operated in a classroom style. One more cause for literature usage is the fact that the literary works could make us learn culture. Thus, literary works, similar to a T.V.'s exposition, movies, videos or newspapers, are important sources for learners to study the culture and way of life of a country.

Again, Collie and Slater (1996: p.5) suggest that "language enrichment is one of the benefits of literature." Literature brings an enrich style in which vocabulary and grammatical words are created much memorized. creation of clauses and the mode of intimating the knowledge could enhance learner's reading and imagination tact. learners who stuck with a drama, a novel or with verse, for a period, is supposed to own the strength to create clues from the context by resorting to contextualized meanings.

Under this mode, learners who study the linguistic style in literary works have to be much innovative in writing, in this way learners estimate and feel the ornamentation of the linguistic forms. Despite the fact, the major deed is to select the suitable author's work for learners. The learners' linguistic measure is one of the much significant slandered of selecting which author's written work. Every stage (beginner, intermediate or advanced) responsible for his own written work and proper learning styles.

Teaching process in fact needs another style and the instructor could bring genuine literary work in an imagination style. learners are normally have the ability to tell their view points and do their utmost to interact. Thus, if they are ready to speak, then oral communication should be a priority.

As Bassnett and Grundy (1993) suggest that "before and after" activities are important supportive for the intermediate level students. By this activity, EFL learners are getting busy in expecting short story beginning and ending. There are double significant stages: before class reading and inside-classroom assignment. The instructor splits learners into double categories and they are to read twice other literary works at their homes. No interaction about the sense of meaning is suggested.

"Gossiping" is different type of literary work which depend on a game for intermediate stage scholars, proposed by (Bassnet and Grundy (1993). It is considered as dramatic work depended on a written work, wellknown short story (Little Red Riding Hood or Brave Heart are good examples here). The instructor writes on the board or spreads to learners a record of benefit sayings, e.g. I must say, if it wasn't for..., I know it isn't her fault, I believe etc. scholars are cheered to chat about the personas, feeling that they are one of them. They are to mention a stage self-saying and act it in explosion of the class. Probably differentiation of this work could be done in a dialogued style. There are many games or activities could be acted or done inside of the classroom like: quote unquote or contrasting and many other ones.

The aforementioned games which depended on thinking knowledge of the skilled proficient similar to Collie and Slater, Maley and Duff or Basnet and Grundy try to come with facts that literary works may form a base element in ELT. The EFL instructor who needs to come out with literary work into the linguistic form class which could suggest to take other example activities which are suggested by the proficient or it could make new class games to be adopted, in accordance with learners or scholars needs, grown and linguistic form stages which are related to their social life.

The universe we live is fast developing and so we have to take so near to learning other languages. Usage of literature to shape the initiative instrument in the teaching operation deep preceding the curricula appears. Literary works have used speaking interactions and literary texts without literary origin, and literature has been waiting for tens of years to be used in the classroom teaching. In current days with the jam of principle and methods of literary works of language learning and teaching process which are obtaining much and much endorsement, and coming back, but with a slogan fresh or modern style.

\section{Conclusion:}

This paper seeks or attempts to obtain a response to the question about whether literature can be used as additional real publications in the development of teaching and learning language in various literary modes and styles.

Literary works are exposed to multiple clarification - they stimulate a lot of students 'personal responses, sympathetically attract them and motivate them to contribute with great enthusiasm to class activities and have a lot more personally and make students responsibly engaged in class assignments, leadership, exploration and creation of many interacting talented language skills.

If the FL instructor is planning to recreate (gravitate) that gravity to read literature in learners by carefully following his first steps and facing the peer in a good learning skill, he must reinforce it to become familiar or practice the use of language in the accreditation method, which begins on their own distinct journey by incorporating The world of oral art and the culture of attractive, focused language.

English language on the side of our country's students who may accomplish a task of solving the process of learning the English language in a smooth manner leading to a simple academic training course, the moderate 
learning process for learning the English language currently exposes the mainly teaching and learning community without using literature Or a targeted culture in the original language. Therefore, curriculum planners, school and literature teachers of English must work together to create a role for approval of teaching institutions in our country which they have be more effective and taken into account. In this study, therefore this study discusses simultaneous coexistence and symbiotic phenomenon between literature and language.

\section{References:}

[1] Ayo. O., Developing EL2 learners' communicative competence through Literature in English, In Oyeleye, (2003).

[2] Ayodele. S. O., The problem of language for educating Nigerian learners, Faculty Lecturer Series No. 4. Ibadan: Faculty of Education. (1988).

[3] Babatunde. S. T., The state of English Language in Nigeria. In I. Lawal, \& Ohia (Eds.), Nigeria. (2002).

[4] Basnett. S., \& Grundy. P., Language through Literature. London: Longman. (2013).

[5] Carter. R., \& Long. M., Teaching Literature. London: Longman. (2014).

[6] Clandfield. Lindsay., What is Literature? One Stop English Magazine, Retrieved USA (2015), April, from http://www.onestopenglish.com , (2005)

[7] Collie. J. \& Stephen. S., Literature in the Language Classroom: A Resource Book of Ideas and Activities, Cambridge: Cambridge University press, (1987).

[8] Collie. J., \& Slater. S., Literature in the Language Classroom. Cambridge: Cambridge University Press. (1987).

[9] Correia. R., Encouraging Critical Reading in the EFL Classroom, English Teaching Forum, (2006).

[10] Hardy. T., Far from the Madding Crowd. retold by Escott, J. Oxford: Macmillan Publishers Limited, (2007).

[11] Keshavazi. Abdollah, The Use of Literature in Teaching English Language, Dept of English Language, Firoozabad, Islamic University, Iran, (2012).

[12] Krashen. S. D., Application of psycho-linguistic research to the classroom, In Methodology in TESOL: A (1987).

[13] Krashen. S. D., Writing: Research theory and application. Oxford: Pensaman Press. (1984).

[14] Lazar. G., Literature and Language Teaching, London: Cambridge University Press. (1993).

[15] O'Connell. F., Get lit up: literature as a teacher's best friend., (2009), Retrieved from http://www.teachingenglish.org.uk/article/get-lit-literature-a-teachers-best-friend

[16] Swant. Datta, Learning English Through Literature: An Old Approach with New Perspectives, TACS College, Dist, Hingoli-Maharashtra, India., (2014)

[17] Teaching English., Using literature - an introduction, (2014), Retrieved from http://www.teachingenglish.org.uk/article/using-literature-introduction 